Rev. Saúde pabt., S. Paulo

4:215-16, dez. 1970.

\title{
LUTZOMYIA FALCIFORMIS (FLOCH \& ABONNENC, 1944) SINÔNIMO DE LUTZOMYIA MONSTRUOSA
} (FLOCH \& ABONNENC, 1944)

\author{
Habib FRAIHA (1) \\ Jeffrey J. SHAW (2) \\ Ralph LAINSON (3)
}

Floch e Abonnenc ${ }^{2,} 3$ descreveram em 1944 L. monstrwosa e $L$. falciformis, a partir de espécimens masculinos e femininos, respectivamente. Essas espécies permaneceram até o momento conhecidas apenas por um dos sexos. Damasceno (3) obteve exemplares machos da primeira, a partir de ovos postos em laboratório por fêmeas identificáveis à segunda. Tal associação, observada por êsse autor em 1945, permaneceu inédita durante todos êstes anos.

Até 1968, no material de nossas coletas figuravam apenas duas fêmeas identifica. das como $L$. falciformis, capturadas com armadilha de Disney ${ }^{1}$, em Utinga, Belém, em maio de 1968.

No decorrer de dezembro do mesmo ano, viríamos confirmar a supracitada informação de Damasceno, com a captura simultânea de 40 machos de $L$. monstruosa e 38 fêmeas de $L$. falciformis, nas áreas do Catu 1 e Catu 2 do Instituto Agronô. mico do Norte (I.A.N.), Belém, em ar- madilha de Disney, tendo como isca um roedor (cobaio ou Proechimys). Nas mesmas coletas foram obtidos 1.297 machos e 3.003 fêmeas de $L$. flaviscutellata, 147 machos e 106 fêmeas de $L$. infraspinosa, 38 machos e 39 fêmeas de $L$. saulensis, 6 machos e 16 fêmeas de $L$. rooti, 1 fêmea de $L$, antunesi e 4 machos de $L$. pinottii, tô. das espécies bem conhecidas em ambos os sexos, inclusive esta última, cuja fêmea ainda não descrita, já identificamos, devendo figurar numa de nossas próximas publicações.

Parece-nos, assim, evidente a associação monstruosa $\mathrm{x}$ falciformis, já confirmada em outras oportunidades, tais como nossas co. letas de janeiro, outubro e novembro de 1969, em Catu 1.

Conseqüentemente, pensamos poder incluir $L$. falciformis na sinonímia de $L$. monstruosa, nome que prevalece por prioridade cronológica.

Recebido para publicactio em 8-4-1970.

(1) Do Instituto Evandro Chagas, Fundacão Serviços de Saúde Pública, Belém, Para, Brasll.

(2) Da Wellcome Parasitology Unit., Belém, Para, Brasil.

(3) Comunicacăo pessoal, 1968. 
H. FRAIHA, H.; SHAW, J. J. \& LAINSON, R. - Lutzomyia falciformis (Floch \& Abonnenc, 1944). Sinônimo de Lutzomyia monstruosa. Rev. Saúde públ., S. Paulo, 4:215-16, dez. 1970.

\section{REFERENCIAS BIBLIOGRAFICAS}

1. DISNEY, R. H. L. - A trap for Phlebotominae sandflies attracted to rats. Bull. Ent. Res., 66:445-451, Jun. 1966.

2. FLOCH, H. \& ABONNENC, E. - Phlébotomes de la Guyane Française (VII). Description de six espèces nouvelles. Publ.
Inst. Pasteur Guyane Territ. Inini, (80), juI. 1944.

3. FLOCH, H. \& ABONNENC, E. - Phlébotomes de la Guyane Francaise (IX). Description de la femelle de $P$. fluviatilis et de trois espèces nouvelles. Publ. Inst. Pesteur Guyane Territ. Inini, (83), aout. 1944. 